\title{
UNCERTAINTY OF MEASUREMENT IN HPM PULSE TESTING
}

\author{
RAFAŁ PRZESMYCKI, MAREK BUGAJ \& MARIAN WNUK \\ Military University of Technology, Poland
}

\begin{abstract}
Immunity measurement of informatic (IT) equipment and specialized military equipment on high power microwave (HPM) pulses are taking on more and more importance. In quite a short time, these tests can become a standard procedure for military and IT systems. The article presents a laboratory stand for the measurement of the immunity of military equipment to HPM pulses along with a description of the measurement procedure. In the research laboratory, one should strive to accredit each of the measurement procedures being carried out. At the Electromagnetic Compatibility Laboratory in the Military University of Technology, the measurement procedure discussed above was prepared for accreditation. One of the basic aspects of accreditation is the determination and assurance of the lowest measurement of uncertainty. The main goal of this article is to present how to determine and calculate the uncertainty budget for the measurement of the immunity of IT equipment and specialized military equipment to HPM pulses.
\end{abstract}

Keywords: electromagnetic pulse, immunity, uncertainty, electromagnetic field, EMC, HPEM, HPM.

\section{INTRODUCTION}

In a high-energy electromagnetic environment of high power, microwave sources are a relatively new kind of threat systems for both military and civilians. Operation using this type of source is usually referred to as intentional electromagnetic disturbance. The High Power Electromagnetic Environments (HPEM), which is inherently harmful, can also occur at frequencies up to several dozen $\mathrm{MHz}$.

Technological development in the field of high-power microwaves has made it possible to produce more efficient microwave sources to irradiate large battle installations. At the same time, it is possible to generate relative high fields strength with the use of compact systems that can fit, for example in a suitcase. That is why the potential threat from High Power Microwave (HPM) has increased. In addition, when the HPM system is applied, especially in combat conditions, by a member of the North Atlantic Treaty Organization (NATO), there may be a need to stage joint defence systems against generated HPM fields. However, in the event of any scenario occurring, the real threat may occur in both friendly and hostile sources and has not yet been fully defined by any NATO member state. For this reason, the information provided below is general and public. National authorities should consult to determine if the HPM environment should be defined for a given system or device [1].

HPM type disruptions can be emitted in the air or be conducted through wires/cables until they reach their intended destination. There are two main possible ways of transmitting electromagnetic energy radiated to electronic systems. This can be done through the "front door" (antenna) or "back door" (cables and openings). Induced currents and voltages can definitively cause damage to electronic systems/circuits to which they reach [1].

The possibility of damaging unprotected electronic systems with disastrous consequences is considered as a realistic scenario for the development of the operational situation, including the critical elements of civilian infrastructure, where the possibility of sabotage and terrorism is a serious problem. A potential attack and additional action using currently and generally available technologies can be taken into account in any situation where a failure of electronic 
systems can have fatal consequences for these systems. The examples concern such issues as: computer security, maintenance-free electronically opened/closed valves, damage to computer data, loss of connectivity and power loss. The result of the disturbance can be even permanent damage to the device. On the other hand, HPM sources belong to the general class of non-lethal weapons that can be used to eliminate hostile capabilities while maintaining a minimum of losses and own damages [1].

\section{HPEM ENVIRONMENT}

Although HPEM effects such as electromagnetic pulse due to lightning (LEMP) and electromagnetic pulse due to the discharge of a nuclear explosion (NEMP) have been studied in the past and the effects of these tests are relatively easy to access, HPM is a relatively new area of research.

Characteristics of hostile sources are unknown and difficult to predict, and possible "friendly" sources, due to the fact that they have not yet been sufficiently defined, should be the subject of security issues. All this makes the determination of the HPM environment very difficult.

Potential attackers can be: criminals, terrorists, dissatisfied employees/clients, soldiers of hostile armed forces/special forces and competitors. Potential scenarios of events using HPM are similar. A dissatisfied employee can bring a small, improvised device to the workplace, and by starting this device may cause numerous problems related to the functioning of electrical, electronic and other infrastructure. To create a threat, a terrorist may use the HPM source installed on the vehicle. In the case of a military approach, it is also possible to use airborne sources.

The characteristics of the threat environment are limited by the attacker's technical skills, the level of technology and access to technological means. The radiated power of HPM sources is from kilowatts to gigawatts (in impulse).

The frequency range is from tens of $\mathrm{MHz}$ to several GHz. Fig. 1 shows the frequency ranges of sources: LEMP, NEMP and HPM sources taken from IEC 61000-2-13 [2].

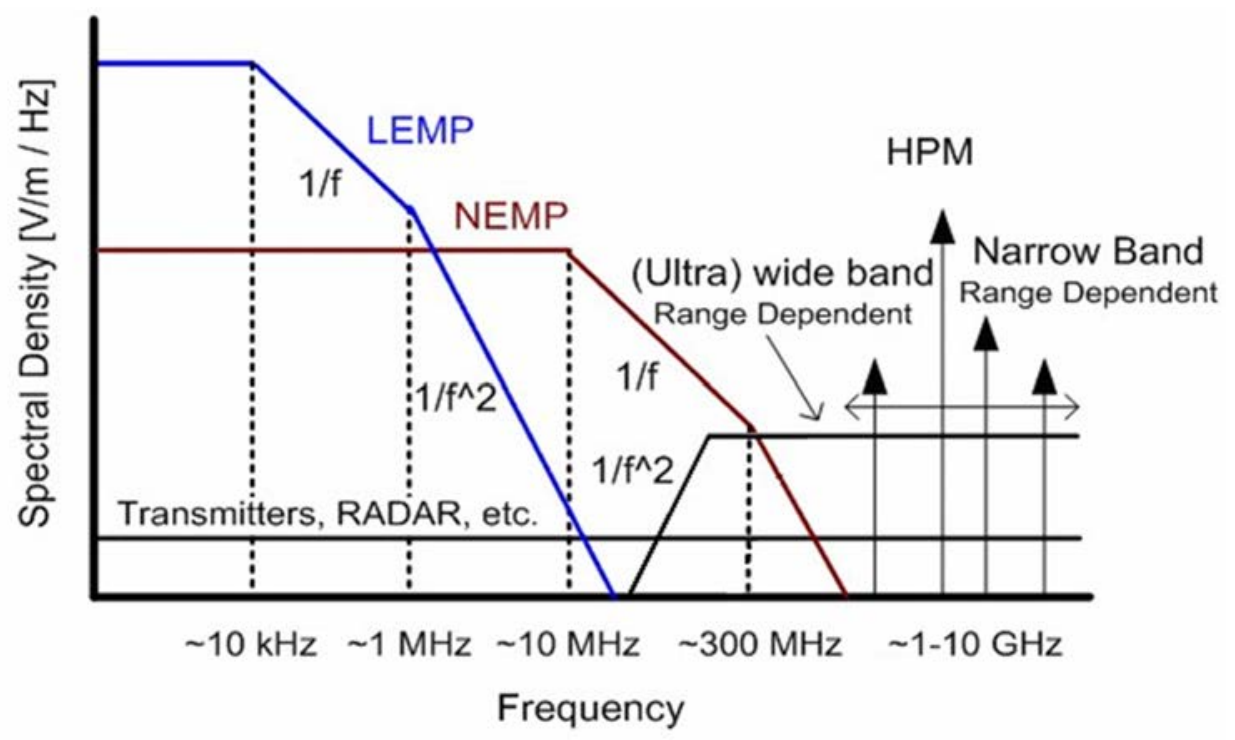

Figure 1: Typical high power electromagnetic environments (HPEM) [1], [2]. 
Depending on the type of objective and the knowledge of the target, to achieve the desired effect and cause the maximum effects, the attacker will choose the types of HPM sources with the most effective course. The possible types of HPM sources and waveforms are described in the next item of the paper. The level of electromagnetic energy at the place of application of the HPM source depends on many parameters [2].

\section{HIGH POWER MICROWAVE PULSE}

HPM sources can be divided into four categories. These are, among others:

a) Mobile HPM sources installed on the platforms - typically HPM sources radiate fields towards the equipment of the facility's infrastructure from areas that are not controlled by devices of the technical protection system, such as areas outside the fence. In this situation, it is more likely to use truck-mounted sources than man-borne sources, because the power required to generate effective levels of electromagnetic fields to radiate the intended target from a considerable distance requires the use of sources characterized by large geometric dimensions and high mass. It is also possible to use sources carried by air.

b) A portable HPM source - a portable HPM source can be brought inside the target - to the site of the object being attacked, hidden under clothing or inside a briefcase, purse or even in a can. The proximity of the electronics subject to attack may cause the "small" source to become even more dangerous than the "larger" source used at a greater distance, because the effect of damping through the screens and distance protections are eliminated.

c) An HPM source that generates conductive disturbances - this type of HPM source can cause energy to be injected directly through the power cords into the facility's infrastructure, such as power lines and communication lines. This type of threat can be caused both from the outside and from the inside of the object.

d) HPM source based on a projectile - an HPM source of this type radiates the entire facility with a generated electromagnetic pulse. This impulse generates a large current impact in the external cables of the facility's infrastructure, such as power lines or communication lines, or in water pipes, etc. [3].

In general, the number of types of HPM waveforms is limited to four. Waveform parameters such as frequency, power, etc. depend on the type of source.

a) The continuous wave (CW) - a HPM system, which generates a $\mathrm{CW}$ waveform, generally contains a magnetron, microwave resonance lamp. The CW waveform signal is most effective when its frequency is tuned to the most susceptible frequency from the point of view of the target. A continuous wave can be characterized by frequency and power [3].

b) Narrowband pulsed CW - narrowband pulsed continuous waveform $\mathrm{CW}$ is a typical HPM waveform. In the Fourier spectrum of this type of wave there is a narrow envelope around the "center frequency". This type of waveform can be characterized by the carrier frequency, peak power, pulse width and pulse repetition frequency and derivative parameters such as duty cycle, average power, etc. The advantage of the shape NB is the fact that a small amount of medium power is used to generate an effective high-energy pulse, which results in the use of this type of high-energy impulses to disturb the work or damage to the electronic equipment. It is assumed that narrow-band sources are characterized by the highest impulse power at the peak. The generated signal is most effective when the target is susceptible to the peak signal at its 
most sensitive frequency. This signal can be designed to engage antennas or antenna structures (coupling through the "front door") to cause damage to the target. Narrowband sources can also be designed to engage with the target through unintentional tracks ("rear door" coupling) causing damage to electronics [3].

c) Dumped sinewave (DS) - DS waveform is characterized by: carrier frequency, peak power, decrement attenuation and energy value in the pulse. The DS waveform is characterized by a "center frequency" and some frequency bands that can increase the likelihood of a "rear door" coupling. The advantage of the DS waveform is a wider band than the CW or NB waveforms; usually one octave [3].

d) Ultra-wide band (UWB) - UWB waveform is characterized by: peak power, rise time, decay time, bandwidth and repetition frequency. UWB pulses are characterized by the ability to excite many resonant modes in a facility or target. Due to the fact that the power that occurs in a small part of the frequency range is relatively small, and also because the total energy is contained in one pulse is small, it is difficult to generate a large field strength in resonance to destruction or damage to the target. In order for the UWB pulses to be effective, more power is required than for the narrowband frequency with the appropriate NB frequency [3].

\section{THE LABORATORY STAND FOR GENERATION AND MEASUREMENT OF HPM PULSE}

The main element responsible for the generation of a HPM pulse is a generator Diehl DS110, which is shown in Fig. 2. It is compact enclosed equipment, looks like a suitcase. Components of the generator are high-voltage power supply, $300 \mathrm{kV}$ Marx generator and a resonant antenna. High voltage power supply system supplies the Marx generator by $50 \mathrm{kV}$ voltage (symmetrical voltage $\pm 25 \mathrm{kV}$ ), he is charged until the threshold set by the switch that sets pressure gas $\mathrm{N}_{2}$ in the generator. When changing the position of the switch, antenna is fed a $300 \mathrm{kV}$ voltage, the sparker contained in the air is isolated by the pressure gas $\mathrm{N}_{2}$ [2],[4]-[6]. The basic specification of the HPM DS110F generator is shown in Table 1.
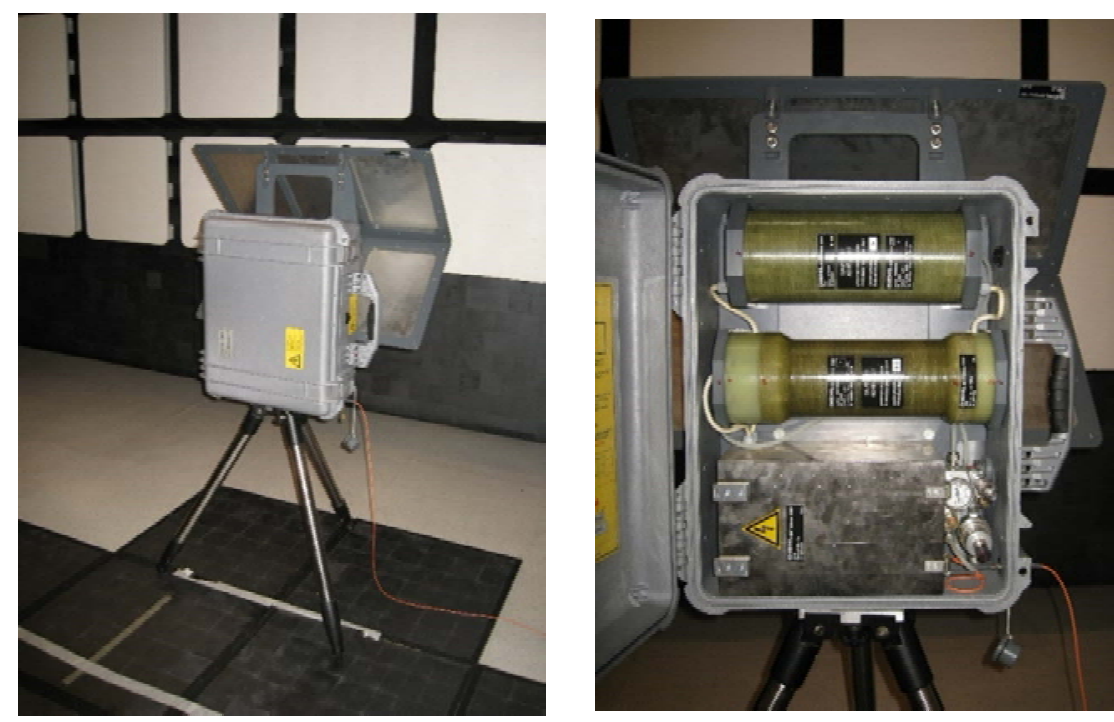

Figure 2: View of the generator Diehl DS 110. 
Table 1: DS110F specifications.

\begin{tabular}{|l|l|}
\hline \multicolumn{1}{|c|}{ Parameter } & \multicolumn{1}{c|}{ Value } \\
\hline Size & $500 \times 410 \times 200 \mathrm{~mm}$ \\
\hline Weight & $24 \mathrm{~kg}$ \\
\hline Peak radiated power & $160 \mathrm{MW}$ \\
\hline Radiation pattern (without reflector) & Dipole \\
\hline Pulse duration & $4 \mathrm{~ns}$ \\
\hline Repetition rate & $>5 \mathrm{~Hz}(10 \mathrm{~Hz})$ \\
\hline Centre frequency & $350 \mathrm{MHz}$ \\
\hline 3 dB bandwidth & $100 \mathrm{MHz}$ \\
\hline Operating time (without reflector) & $>1 \mathrm{~h}$ \\
\hline
\end{tabular}

The Diehl Measurement System incorporates a fast digitizing oscilloscope running from an uninterruptible power supply (UPS). The UPS is used in a different manner than originally intended. The UPS operates the oscilloscope for up to $3 \mathrm{~h}$ without mains connection before recharging the batteries of the UPS is required.

Oscilloscope and UPS are installed in a shock damped and electromagnetically shielded housing. This allows not only outdoor measurements without mains available, but also shielded measurements without any connection to outer environment except the field measuring probe.

The Diehl Measurement System combines a state-of-the-art Tektronix Digital Phosphor Oscilloscope with a computer UPS and an additional battery pack within a shielded and shock damped housing. Due to this combination the Diehl Measurement System can be operated e.g. in free field without mains, and it can be operated with closed shielding lids when in close distance to radiating HPM systems. The Diehl Measurement System includes a socalled D-dot probe and a Balun which are designed to measure pulsed electromagnetic fields. Within the shielded housing a laptop computer is stored usable to calculate measured electromagnetic fields and to further process measured data [2], [4]-[6].

Fig. 3 shows an appearance of HPM pulse in the time domain, while Fig. 4 shows the frequency spectrum of the pulse. The red color presented the pulse generated by generator with reflector, the blue color presented the pulse generated by generator without reflector.

\subsection{D-dot field probe}

For measuring fast HPM pulses with the Diehl Measurement System a combination of D-dot probe Prodyn AD-70 and a Balun Prodyn BIB-170F was chosen as the optimum free field sensor. The probe is mounted on a plastic stand to reduce measurement influences to a minimum. Free field sensors as the Prodyn AD-70 are dual sensors. They have two antenna elements that are sensitive to the same field but measure in opposite directions. They have their own ground reference between the two elements. Electric (D-dot) sensors have capacitive sensing elements in opposite to magnetic (B-dot) sensors having inductive sensing elements or loops. The D-dot sensors measure time derivative of electric displacement. The 
PI-78 Computational Methods and Experimental Measurements XIX

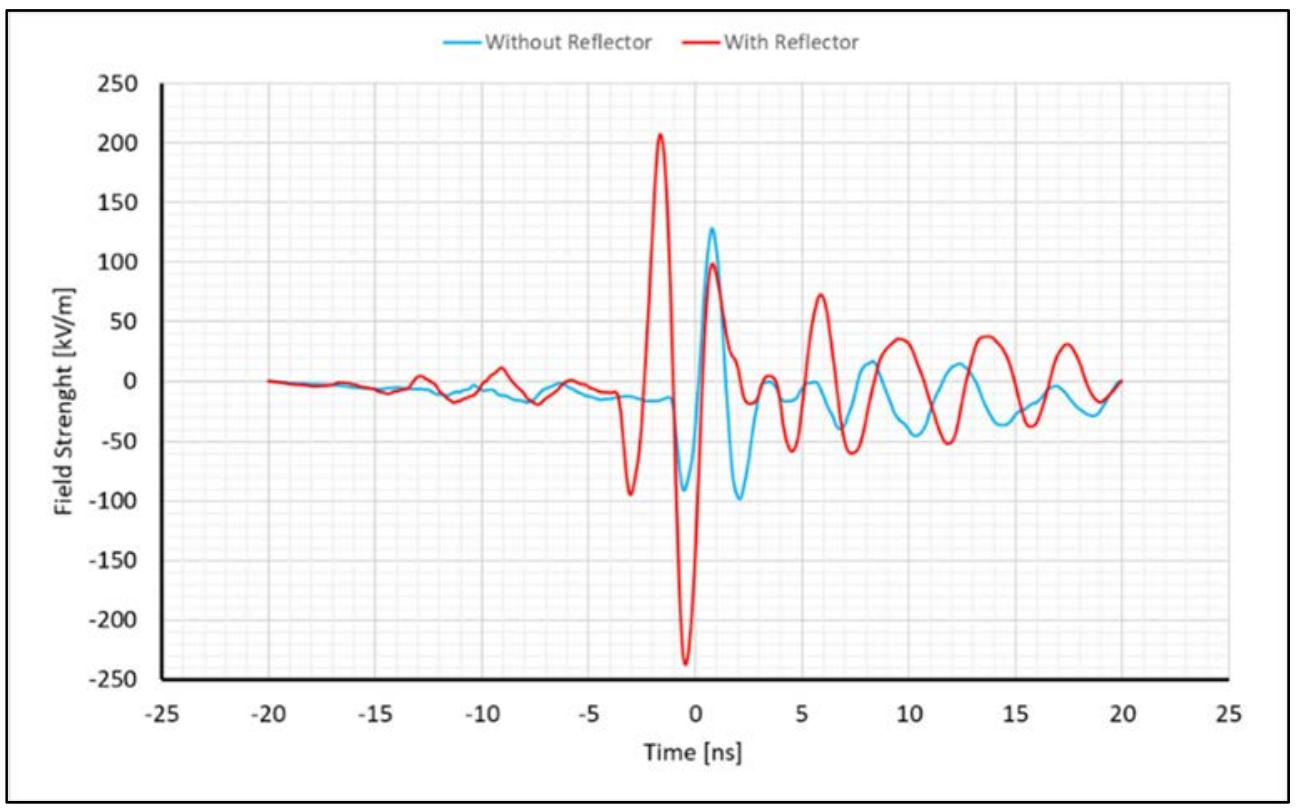

Figure 3: An example of the time domain for a sample HPM pulse.

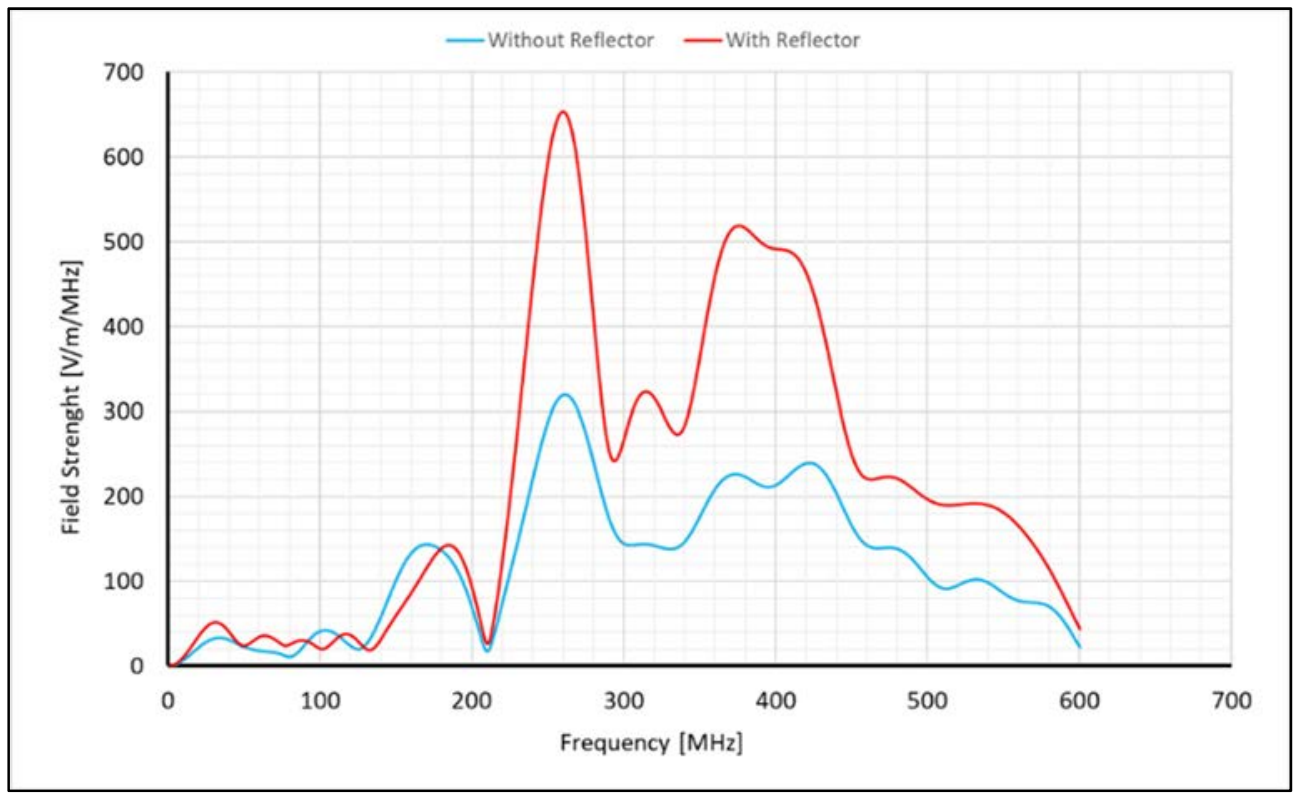

Figure 4: An example of the frequency spectrum for a sample HPM pulse. 
sensor is passive devices and does not need external power supply. Since the sensor is symmetric a Balun is required. Balun is the abbreviation for BALanced and UNbalanced and describes a unit which converts the symmetric probe signals to a common, non-symmetric signal as usual in coaxial cables. The D-dot effective antenna size of $0.001 \mathrm{~m}^{2}$ as well as the Balun insertion loss of $8 \mathrm{~dB}$ are included as standard parameters within the Excel macros. These values can be changed in Microsoft Excel worksheet when using probes other than the original ones delivered with the Diehl Measurement System [6].

\subsection{Oscilloscope}

The main component of Diehl Measurement System is a state-of-the-art Tektronix Digital Phosphor Oscilloscope DPO70404. It contains four analogue channels each having $4 \mathrm{GHz}$ bandwidth and $25 \mathrm{GS} / \mathrm{s}$ real time sampling rate. For pulsed field measurement of Diehl Measurement System an interpolated higher sampling rate is not usable, the real time sampling method is always to be used. The Tektronix DPO70404 incorporates an own computer board for operating the equipment. It would be possible to install Microsoft Excel with processing macros but Diehl experience is that using a separate computer makes the oscilloscope more stable and data analysis more independent. The oscilloscope allows to record so-called FastFrame formats. FastFrame is able to capture many trigger events respectively many HPM pulses as sequential records in a larger single record. It is possible to view and measure each record individually. Time stamps display the absolute trigger time for a specific frame and the relative time between triggers of two specified frames. This means that several HPM pulses can be stored within one file and can be processed in the computer in one step. Data measured with the oscilloscope can be stored either on internal hard disk, on USB sticks connected at back or front USB ports or directly on network drives when connected with other computers. Diehl recommends storing measured data first on internal hard disk. To copy them onto the laptop computer use either USB memory sticks or network connection. This ensures that only a duplicate copy is onto the laptop computer when processing measured data [6].

The output of the D-dot sensor is proportional to the first time derivative of the electric displacement $\mathrm{D}(\mathrm{t})$, that is:

$$
\mathrm{D}-\mathrm{dot}=\mathrm{dD} / \mathrm{dt}
$$

and, rewriting equation:

$$
\mathrm{Vo}_{\mathrm{o}}=\mathrm{R} \text { Aeq } \mathrm{dD} / \mathrm{dt} \text {, or } \mathrm{dD} / \mathrm{dt}=\mathrm{Vo} / \mathrm{R} \text { Aeq, }
$$

then, recalling that $\mathrm{D}=\varepsilon_{\mathrm{o}} \mathrm{E}$ :

$$
\mathrm{dE} / \mathrm{dt}=\mathrm{Vo} / \mathrm{R} \text { Aeq } \varepsilon_{0}
$$

The output of the D-dot sensor is measured in volts that are proportional to units the first time derivative of electric displacement $\mathrm{dD} / \mathrm{dt}$, coulombs per sq $\mathrm{m}$. The constant of proportionality between the sensor output and the first time derivative of the electric field $\mathrm{dE} / \mathrm{dt}\left(=\mathrm{dD} / \mathrm{dt} \varepsilon_{\mathrm{o}}\right)$ is the permittivity constant $\varepsilon_{\mathrm{o}}$. The constant of proportionality between the sensor output $\mathrm{Vo}$ and the first time derivative of the electric field $\mathrm{dE} / \mathrm{dt}$ is the product of the output impedance R and the equivalent area Aeq of the sensor, and the permittivity constant $\varepsilon_{0}$. This is the calibration factor, but it is applied to the first time derivative of the electric field, $\mathrm{dE} / \mathrm{dt}$, not to the electric field itself [7].

The sensor output resulting is a cosine function with amplitude $V_{\text {op }}$ and frequency $f$, where: 


$$
\mathrm{Ep}=1 / 2 \mathrm{f}(\mathrm{dE} / \mathrm{dt}) \mathrm{p}=\mathrm{V}_{\mathrm{op}} / 2 \mathrm{f} \mathrm{R} \text { Aeq } \varepsilon_{\mathrm{o}}
$$

\subsection{Complete measurement chain}

Since the output signal of the D-dot sensor is balanced, but the input of an oscilloscope is singled-ended, a balanced-to-unbalanced transformer (Balun) is directly connected to the sensor. This device adds a specific insertion loss to the sensor signal and performs an impedance transformation from the balanced sensor output (typically $100 \Omega=2 \cdot 50 \Omega$ to a coaxial output (typically $50 \Omega$ ) [8].

Before the output signal from the D-dot probe is registered by the oscilloscope, it must be sent. There are two types of data transfer from the D-dot probe to the oscilloscope. The first of them is based on high-frequency tracks (concentric lines) that directly connect the D-dot probe, Balun and oscilloscope. Due to high amplitudes of HPM pulses, shielding of RF lines however, it can be a big problem. It is possible to use a second type of data transfer using a short coaxial connection that is used from the Balun to the optical transmitter. The optical transmitter converts this signal into an optical signal. The optical signal is sent via optical fiber to the receiver, which converts back to an electrical signal. In practice, the D-dot probe is directly connected to the Balun. In developed laboratory stand there are only RF paths. This is a first type of data transfer from the D-dot probe to the oscilloscope.

The Fig. 5 has been presented a block diagram of the laboratory stand to generation and measurement of HPM pulse. The main elements of this laboratory stand are the Diehl generator and field probe, which they are placed in an anechoic chamber so that the probability of damage other electronic devices located near the generator is very small. In addition, they have been placed on the metal floor with ferrite absorbers thus ensuring that a common reference mass. Devices in the measurement room allow their safe operation by authorized persons. Fig. 6 shows a schematic with only every component used for the field measurement.

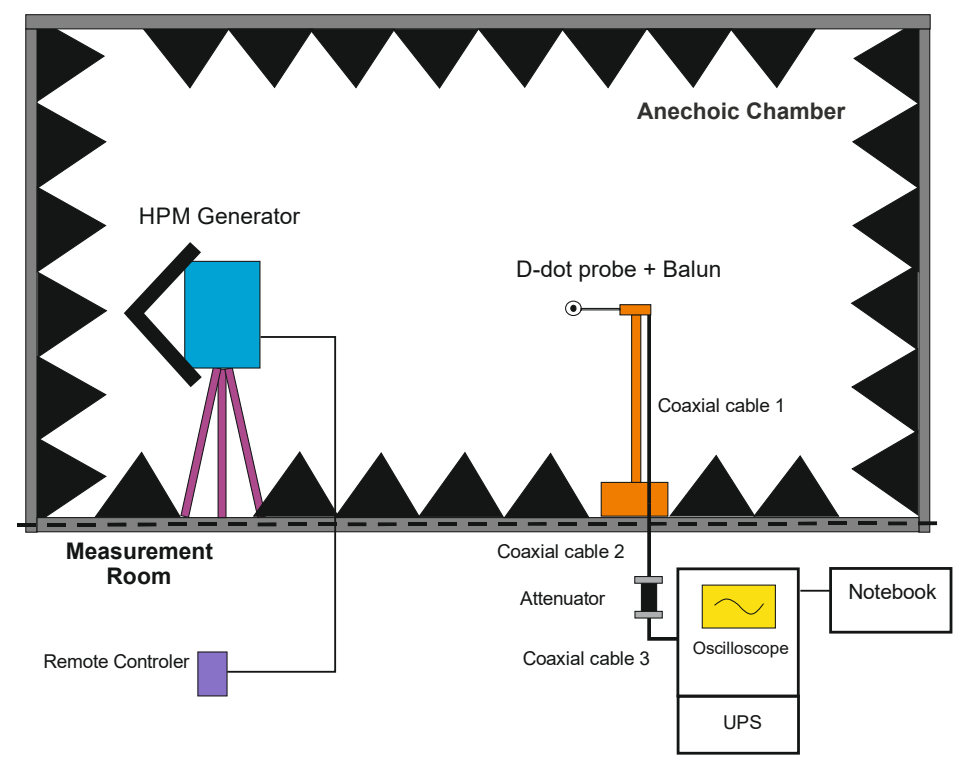

Figure 5: The block diagram of the laboratory stand for the generating and measurement of a HPM pulse. 
Anechoic Chamber

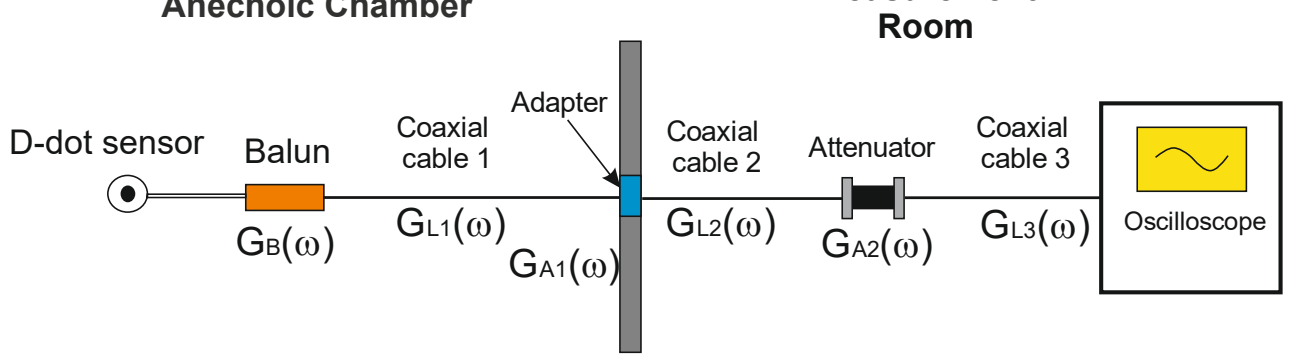

Figure 6: Schematic of the measurement chain for the field measurement in the laboratory stand for the measurement of a HPM pulse.

The complete signal path of course must be considered non-ideal, because each component modifies the original signal from the output of the D-dot sensor. The influence of each component on the value of the received signal can be described by means of complex transfer functions in which $G_{B}(\omega)$ is for Balun, $G_{L 1}(\omega), G_{L 2}(\omega), G_{L 3}(\omega)$ for coaxial cables, $\mathrm{G}_{\mathrm{A} 1}(\omega), \mathrm{G}_{\mathrm{A} 2}(\omega)$ for the adapter in the chamber wall and silencer. These complex transfer functions describe the amplitude response and linear phase difference of each element depending on the angular frequency $\omega$ as a linear system. The data for each element of the measurement chain can easily be obtained by measuring $\mathrm{S}_{21}$ using a vector analyzer VNA $[8]$.

\section{UNCERTAINTY OF MEASUREMENT FOR LABORATORY STAND TO GENERATION AND MEASUREMENT OF HPM PULSE}

The traceability of measurement quantities is very important for an accredited test procedure. Accuracy and reliability of measurement results are based on the uncertainty budget. Starting from the model equation, you can calculate the uncertainty budget for the presented measurement station. In this type of measurements very often logarithmic values are used for particular quantities, which simplifies the final formulas for uncertainty budget calculations. The equation for the measurement chain described and shown in Fig. 6 is as follows:

$$
E(t)=E_{\text {calc }}(t)+d V_{\text {scope }}(t)+d V_{\text {sensor }}(t)+P_{S}+\sum d E R_{x},
$$

where Table 2 describes the components included in the uncertainty budget. Due to the complete consideration of the complex measuring chain, the transmission functions of each element depending on the angular frequency reduce their contribution to the uncertainty budget only to components derived from $\mathrm{S}_{21}$ measurements for each of them [8], [9]:

$$
\sum d E R_{x}=d E R_{B}+d E R_{L 1}+d E R_{L 2}+d E R_{L 3}+d E R_{A 1}+d E R_{A 2} .
$$

Table 3 shows the full calculation of the expanded measurement uncertainty for the measuring stand discussed, including source uncertainty and assumed distributions. The calculations were based on the literature [10], [11].

For the presented test method for measuring the amplitude of HPM pulses, the expanded measurement uncertainty can be determined to $\mathrm{be} \pm 3.08 \mathrm{~dB}$. The expansion factor $\mathrm{k}=2.0$ is dictated by additional degrees of freedom due to type A errors during the analysis of all components derived from measurements $\mathrm{S}_{21}$. 
Table 2: Uncertainty budget.

\begin{tabular}{|c|c|c|c|c|c|c|c|}
\hline Symbol & Source of uncertainty & Value & $\begin{array}{l}\text { Probability } \\
\text { distribution }\end{array}$ & Divisior & $C_{i}$ & $u_{i}(y)$ & $\left(u_{i}(y)\right)^{2}$ \\
\hline $\begin{array}{c}E_{\text {calc }}(t) \\
{[\mathrm{dB}]}\end{array}$ & Estimation & 0.50 & Rectangular & 1.732 & 1 & 0.289 & 0.083 \\
\hline $\begin{array}{l}d V_{\text {scope }}(t) \\
{[\mathrm{dB}]}\end{array}$ & $\begin{array}{l}\text { Calibration certificate or } \\
\text { documentation and the } \\
\text { conformity certificate of } \\
\text { the oscilloscope }\end{array}$ & 0.65 & Rectangular & 1.732 & 1 & 0.375 & 0.141 \\
\hline $\begin{array}{c}d V_{\text {sensor }}(t) \\
{[\mathrm{dB}]}\end{array}$ & $\begin{array}{l}\text { Estimation from } \\
\text { reference measurement } \\
\text { within an Anechoic } \\
\text { chamber }\end{array}$ & 1.9 & $\begin{array}{l}\text { Normal, } \\
\mathrm{k}=2\end{array}$ & 2.000 & 1 & 0.950 & 0.903 \\
\hline $\begin{array}{c}P_{S} \\
{[\mathrm{~dB}]}\end{array}$ & $\begin{array}{l}\text { Verification } \\
\text { measurement before } \\
\text { each test }\end{array}$ & 2.0 & $\begin{array}{l}\text { Normal, } \\
\mathrm{k}=2\end{array}$ & 2.000 & 1 & 1.000 & 1.000 \\
\hline $\begin{array}{c}d E R_{B} \\
{[\mathrm{~dB}]}\end{array}$ & $\begin{array}{l}\text { Calibration certificate or } \\
\text { documentation and the } \\
\text { conformity certificate of } \\
\text { the vector network } \\
\text { analyzer }\end{array}$ & 0.35 & Rectangular & 1.732 & 1 & 0.202 & 0.041 \\
\hline $\begin{array}{c}d E R_{L 1} \\
{[\mathrm{~dB}]}\end{array}$ & $\begin{array}{l}\text { Calibration certificate or } \\
\text { documentation and the } \\
\text { conformity certificate of } \\
\text { the vector network } \\
\text { analyzer }\end{array}$ & 0.35 & Rectangular & 1.732 & 1 & 0.202 & 0.041 \\
\hline $\begin{array}{c}d E R_{L 2} \\
{[\mathrm{~dB}]}\end{array}$ & $\begin{array}{l}\text { Calibration certificate or } \\
\text { documentation and the } \\
\text { conformity certificate of } \\
\text { the vector network } \\
\text { analyzer }\end{array}$ & 0.35 & Rectangular & 1.732 & 1 & 0.202 & 0.041 \\
\hline $\begin{array}{l}d E R_{L 3} \\
{[\mathrm{~dB}]}\end{array}$ & $\begin{array}{l}\text { Calibration certificate or } \\
\text { documentation and the } \\
\text { conformity certificate of } \\
\text { the vector network } \\
\text { analyzer }\end{array}$ & 0.35 & Rectangular & 1.732 & 1 & 0.202 & 0.041 \\
\hline $\begin{array}{c}d E R_{A 1} \\
{[\mathrm{~dB}]}\end{array}$ & $\begin{array}{l}\text { Calibration certificate or } \\
\text { documentation and the } \\
\text { conformity certificate of } \\
\text { the vector network } \\
\text { analyzer }\end{array}$ & 0.35 & Rectangular & 1.732 & 1 & 0.202 & 0.041 \\
\hline $\begin{array}{c}d E R_{A 2} \\
{[\mathrm{~dB}]}\end{array}$ & $\begin{array}{l}\text { Calibration certificate or } \\
\text { documentation and the } \\
\text { conformity certificate of } \\
\text { the vector network } \\
\text { analyzer }\end{array}$ & 0.35 & Rectangular & 1.732 & 1 & 0.202 & 0.041 \\
\hline $\begin{array}{c}\mathrm{u}_{\mathrm{c}}(\mathrm{E}(\mathrm{t})) \\
{[\mathrm{dB}]}\end{array}$ & $\begin{array}{l}\text { Combined standard } \\
\text { uncertainty }\end{array}$ & & Normal & & & 1.540 & 2.372 \\
\hline $\begin{array}{c}\mathrm{U}(\mathrm{E}(\mathrm{t})) \\
{[\mathrm{dB}]}\end{array}$ & Expanded uncertainty & & $\begin{array}{c}\text { Normal } \\
\mathrm{k}=2\end{array}$ & & & 3.08 & \\
\hline
\end{tabular}


Table 3: Uncertainty contributions.

\begin{tabular}{|l|l|l|l|}
\hline Symbol & Quantity & Unit & Description \\
\hline$E(t)$ & Electrical field strength & $\mathrm{dB} \mu \mathrm{V} / \mathrm{m}$ & This is a result of measurements \\
\hline$E_{\text {calc }}(t)$ & $\begin{array}{l}\text { Calculated electrical field } \\
\text { strength }\end{array}$ & $\mathrm{dB} \mu \mathrm{V} / \mathrm{m}$ & $\begin{array}{l}\text { This is a value calculated from } \\
\text { the sample data in oscilloscope }\end{array}$ \\
\hline$d V_{\text {scope }}(t)$ & $\begin{array}{l}\text { Amplitude error of the } \\
\text { oscilloscope }\end{array}$ & $\mathrm{dB}$ & $\begin{array}{l}\text { Amplitude error of the } \\
\text { oscilloscope }\end{array}$ \\
\hline$d V_{\text {sensor }}(t)$ & $\begin{array}{l}\text { Output error of D-dot probe } \\
P_{S}\end{array}$ & $\mathrm{~dB}$ & $\begin{array}{l}\text { This value summarizes all the } \\
\text { imperfections of the field probe }\end{array}$ \\
\hline$\sum d E R_{x}$ & $\begin{array}{l}\text { Sum of errors from the } \\
\text { measurement chain }\end{array}$ & $\mathrm{dB}$ & $\begin{array}{l}\text { This value is an estimation for } \\
\text { the repeatability of the } \\
\text { measurement, e.g. the } \\
\text { placement of the sensor }\end{array}$ \\
\hline $\begin{array}{l}\text { Mhis value is the overall error } \\
\text { from the } \mathrm{S}_{21} \text { measurement of the } \\
\text { measurement chain's elements }\end{array}$ \\
\hline
\end{tabular}

\section{CONCLUSIONS}

The study of the resistance of specialist military equipment to the pulsed electromagnetic field is getting more and more important. In quite a short time, these tests can become a standard procedure for military and IT systems. The testing procedures in standardization documents defining risk levels and testing procedures for HPM exposure have existed for several years. This article presents the measurement procedure and the laboratory stand for immunity test of military equipment to pulsed electromagnetic fields.

In the research laboratory one should strive to accredit each of the performed measurement procedures. At the Electromagnetic Compatibility Laboratory in Military University of Technology, the measurement procedure discussed above was prepared for accreditation. One of the basic aspects of accreditation is the determination and assurance of the least possible measurement uncertainty.

The main purpose of this article, however, was to present the method of determining and calculating the budget of uncertainty for immunity test of specialist military equipment to pulsed electromagnetic fields. Due to mathematical relations, which take into account all the information of the measuring chain from the point of view of electrical parameters, the expanded uncertainty of measurement is $3.08 \mathrm{~dB}$ for the discussed measuring stand. Using this test method, you can offer reliable and repeatable qualification tests for HPM compromising military equipment, which rely on the accuracy and reliability of such tests.

\section{REFERENCES}

[1] AECTP 250 Ed.2, 2011: Electrical and electromagnetic environmental conditions. NATO International Staff - Defence Investment Division, 2011.

[2] Przesmycki, R. \& Wnuk, M., Susceptibility of IT devices to HPM pulse. International Journal of Safety and Security Engineering, 8(2), pp. 223-233, 2018. 
[3] NO-06-A218-4, 2014 - Technika wojskowa, Warunki Środowiskowe Część 4: Elektryczne i elektromagnetyczne oddziaływania środowiskowe, 2014.

[4] Przesmycki, R., Wnuk, M. \& Bugaj, M., HPEM susceptibility assessment of data storage devices. 21st International Conference on Microwave, Radar and Wireless Communications (MIKON), Kraków, Poland, 2016.

DOI: 10.1109/MIKON.2016.7492113.

[5] Przesmycki, R. \& Wnuk, M., HPEM susceptibility assessment of informatic devices. Progress in Electromagnetic Research Symposium (PIERS), Shanghai, China, 2016. DOI: 10.1109/PIERS.2016.7734568.

[6] DIEHL BGT Defence, Operating and Maintenance Manual for DIEHL DS110.KS2.F.MP1.B (HPM Case System DS110), document No BDB8118952.

[7] Reed Edgel, W., The Next Best Thing to Calibration, Functional Testing, Prodyn Aplication note.

[8] Kreitlow, M., Schmidt, G. \& Sabath, F., Accreditation of a NEMP test procedure: Approach, measurement technique, uncertainty. 2016 IEEE International Symposium on Electromagnetic Compatibility (EMC), Ottawa, ON, pp. 841-846, 2016.

[9] Kreitlow, M., Schmidt, G. \& Sabath, F., The Uncertainty of Measurement in NEMP Testing, July 2016.

[10] BSI, General Requirements for the Competence of Testing and Calibration Laboratories, International Organization for Standardization (ISO) Std. ISO 17 025:2005, 2005.

[11] BIPM, Evaluation of measurement data - Guide to the expression of uncertainty in measurement (GUM), Joint Committee for Guides in Metrology (JCGM/WG 1), 2008. www.bipm.org/utils/common/documents/jcgm/JCGM 1002008 E.pdf. 